\title{
Genetic Diversity of Banana Bunchy Top Virus (BBTV) Prevalent in Assam Causing Banana Bunchy Top Disease
}

\author{
Nilakshi Kakati* and P.D. Nath \\ Department of Plant Pathology, Assam Agricultural University, Jorhat-785013, Assam, India \\ *Corresponding author
}

\section{A B S T R A C T}

Molecular detection of Banana Bunchy Top Virus (BBTV) was carried out using nucleic acid based polymerase chain reaction (PCR) method with six different primer pairs for the

Keywords

Banana bunchy top virus, Banana bunchy top disease, PCR, Sequence analysis

Article Info

Accepted:

12 October 2018

Available Online:

10 November 2018 six components of BBTV (DNA1 to DNA6) genome. Samples were collected from six banana cultivars exhibiting the characteristic symptoms Banana bunchy top disease from eight districts of Assam viz., Jorhat, Golaghat, Sonitpur, Morigaon, Nagaon, Kamrup Metro, Kamrup Rural and Goalpara. All the primer pairs detected the BBTV positive samples giving a band size of $1111 \mathrm{bp}$ for DNA 1, $1058 \mathrm{bp}$ for DNA 2, $1075 \mathrm{bp}$ for DNA 3, 1046 bp for DNA 4, 1018 bp for DNA 5 and 1089 bp for DNA 6. Results revealed the prevalence of BBTV in all the surveyed banana orchards. Twelve PCR products were partially sequenced and compared with those of BBTV reported previously. The sequence similarity and phylogenetic analysis showed 86.00 to 99.00 per cent similarity with known isolates of Pacific Indian Ocean (PIO) group members of BBTV. However, two isolates showed 94 to 95 per cent similarity with members of South-East Asian (SEA) group of BBTV. Present investigations showed an indication of prevalence of genetic distinctiveness of BBTV Assam isolates with known Indian isolates.

\section{Introduction}

Banana, a fruit of great socio-economic significance is the largest fruit crop of India accounting approximately 35 per cent of its total fruit production. India is the largest producer of bananas and plantains with an annual production of 29.78 million tonnes from an area of 0.748 million ha and accounts for 22.15 per cent of the world's production whereas Assam ranks $9^{\text {th }}$ position in terms of production amongst the twelve banana growing states of India with an annual production of $0.835 \mathrm{mt}$ from an area of 0.054 mha (NRCB website). Banana plantains are subjected to various natural calamities, but diseases in particular, viral diseases constitute a major setback to this crop worldwide. Among viral infections, Banana bunchy top disease (BBTD) is the most serious and devastating disease of Banana (Musa spp.) caused by a multi component ssDNA virus Banana Bunchy Top Virus (BBTV) belongs to the genus Babuvirus and family Nanoviridae (Allen, 1987). Isometric virions of BBTV are approximately $18-20 \mathrm{~nm}$ in diameter (Iskra $e t$ al., 1997) consist of six circular single stranded DNA molecules ( $1 \mathrm{~kb}$ each) as a part 
of its genome (Karan et al., 1997). Each strand except DNA 1 codes for a single protein, and these are responsible for its replication, multiplication and virulence (Beetham et al., 1999). The virus is persistently transmitted by banana aphid Pentalonia nigrnervosa (Thomas et al., 1991; Magee, 1927) from plant to plant and from place to place by people transporting planting materials obtained from infected plants.

The symptoms caused by BBTV include bunched appearance at the top of the plant with narrow, upright and erect leaves, which are yellowed at the margins. The leaves become increasingly smaller and the plant becomes dwarfed. Due to short and erect leaves, severe resetting occur which leads to bunchy top appearance of the plant (Khalid et al., 1993). The characteristic symptoms of the disease are the small dark green streaks on the pseudostem, petioles and leaves resulting in a dot-dash or "morse code" pattern (Dale and Harding, 1998). These dark streaks often extend down the midrib and petiole (Thomas et al., 1994). Green J-hook symptoms occur where the flat part of the banana leaf meets the midrib. These are the parallel dark green streaks terminate at the leaf midrib with a distinct, J-hooking pattern which are very reliable indicator of BBTD. When young plants are infected with BBTV, they usually do not flower. "Dot and dashes" or "morse code" symptoms appear on the reddish flower bracts of the bellflower. Depending on the time of infection, the infected plants do not produce fruits and if produced, the banana fingers and bunched may be stunted, twisted or otherwise deformed and of little use (Dale, 1987; Akram and Kumar, 2006).

The only known control method of BBTD is identifying diseased plants and destroying them in the field. In the absence of any known resistance to this virus, early identification of diseased material is paramount to prevent large scale propagation of diseased plants through tissue culture in Indian farming. Quarantine restrictions and virus-free planting material certification are the most efficient methods of BBTV management. All these require timely and accurate diagnosis of diseased plants. A number of methods have been developed for detection and diagnosis of BBTV. Traditional methods like symptomatology and transmission study widely used but these are not very reliable and accurate. Symptoms vary based on virus strain, banana species/ cultivar, time of infection and environment. Also plants exhibit virus like symptoms as a result of abiotic stresses like nutrient imbalances. Transmission studies are very time consuming, labour intensive and requires a large population of vectors and chances of human error is very high and hence not very practical. Detection through electron microscope is sensitive but it can be used for testing a few samples and its availability is confined to a few sophisticated laboratories. Serological methods like ELISA are relatively specific, sensitive and reliable in detecting of BBTV but Banana Bunchy Top Virus are very difficult to purify due to presence of large amount of latex and phenolic compounds in the banana plant, which interfere the virus extraction and purification and thus hard to produce polyclonal antibodies. Therefore, we have to depend on commercial antibody which is very expensive. The latest and the most reliable, accurate method of BBTV detection is nucleic acid based/ molecular method i.e. polymerase chain reaction method (PCR). PCR has exceptional sensitivity and it is 1,000 times more sensitive than dot-blot and ELISA. It can detect BBTV in concentrations as low as picograms. Furthermore, it also enables us to go for determination of genetic variability among BBTV isolates and sequencing of amplified product. Detection of virus even in non-symptomatic host plant, which reduce the yield loss as due to early identification of 
disease in the nursery itself provide the grower or farmer to replace the diseased crop in the nursery or in the main field with healthy crop or to undertake necessary protection against the disease as early as possible. Based on this the present study was conducted to detect banana bunchy top disease in different banana growing districts of Assam using nucleic acid based PCR assay.

\section{Materials and Methods}

Survey was conducted in eight major banana producing districts of Assam viz., Jorhat, Golaghat, Sonitpur, Morigaon, Nagaon, Kamrup Metro, Kamrup Rural and Goalpara for collection of banana Samples. Both infected and healthy leaf samples were collected.

For PCR, analysis, genomic DNA was extracted and purified from $200 \mathrm{mg}$ of young leaf and/or midrib tissues samples as mentioned by Lokeswari et al., (2007) with modification. This mid rib tissues were grinded and tissue contents were squeezed out using addition of extraction buffer containing 100mM Tris ( $\mathrm{pH} \mathrm{8),} 50 \mathrm{mM}$ EDTA (pH 8), $500 \mathrm{mM} \mathrm{NaCl}$ and $2 \mathrm{mM} \beta$ - mercaptaethanol. Liquid content of the leaf mid rib was collected and sodium dodecyl sulfate $(0.5 \%)$ was then added to it and incubated at $65 \mathrm{C}$ for $10 \mathrm{~min}$. About $160 \mu \mathrm{l}$ of $5 \mathrm{M}$ potassium acetate was then added to the sample and centrifuged at $10,000 \mathrm{rpm}$ for $10 \mathrm{~min}$ at $4^{\circ} \mathrm{C}$. After centrifugation, supernatant is taken and 0.7 volume of Isopropyl alcohol was added. Samples were then centrifuged at $10,000 \mathrm{rpm}$ for $10 \mathrm{~min}$ and the pellet containing the DNA was retained. Pellet was washed with $70 \%$ ethanol $(500 \mu \mathrm{l})$, air dried and then suspended in $50 \mu \mathrm{l}$ TE containing $10 \mathrm{mM}$ Tris $(\mathrm{pH} 8)$ and $1 \mathrm{mM}$ EDTA ( $\mathrm{pH} \mathrm{8)}$. Isolated genomic DNA of different samples was quantified using nano drop and the DNA quality confirmation was done using gel electrophoresis.
For Polymerase chain reaction (PCR) six different BBTV specific primer pairs (DNA 16) were used for amplification (Table 1). For each PCR, a $25 \mu$ l reaction mixture was prepared containing, $2 \mu \mathrm{l}$ of target DNA as a template, $2.5 \mu 1$ of $10 \mathrm{X}$ PCR buffer (with 17.5 $\mathrm{mM} \mathrm{MgCl} 2), 2.0 \mu \mathrm{l}$ of $10 \mathrm{mM}$ dNTPs, $2.0 \mu \mathrm{l}$ of each forward and reverse primers $(10 \mathrm{pmol} /$ $\mu 1), 1.8 \mu \mathrm{l}$ of Taq DNA polymerase $(1 \mathrm{U} / \mu \mathrm{l})$ and $12.7 \mu \mathrm{l}$ of nuclease free water. Constituents were mixed well by vortexing and the PCR was run in a thermal cycler (Applied Biosystem Pvt. Ltd.) at $94{ }^{\circ} \mathrm{C}$ for 3 min, followed by 40 cycles of denaturation $\left(94^{\circ} \mathrm{C}\right.$ for $\left.1 \mathrm{~min}\right)$, annealing $\left(50{ }^{\circ} \mathrm{C}\right.$ for $\left.1 \mathrm{~min}\right)$ and extension $\left(72{ }^{\circ} \mathrm{C}\right.$ for $\left.1 \mathrm{~min}\right)$ and then finally, one cycle at $72{ }^{\circ} \mathrm{C}$ for $10 \mathrm{~min}$ for final extension and $4{ }^{\circ} \mathrm{C}$ for infinity. The cycling condition was the same for all the primers used except that the annealing temperature was $55^{\circ} \mathrm{C}$ when BBTV 5 and BBTV 6 primers (Table 1) were used. The PCR products were analysed in 1.2 per cent agarose gel (Appendix IV) electrophoresis in $1 \mathrm{X}$ TBE buffer containing $0.5 \mu \mathrm{g} / \mathrm{ml}$ of Ethidium bromide. Migrated DNA was visualized using a UV transilluminator and size of the amplicons were estimated comparing with 100 bp DNA marker. The gel images were captured using the geldoc (Alpha Innotech, USA). PCR fragment obtained from twelve BBTV infected samples from three cultivars viz., Jahaji (Jorhat district), Chenichampa (Nagaon district) and Malbhog (Morigaon district) were partially sequenced at Bioserve Biotechnology (I) Pvt. Ltd, Hyderabad. Sequenced products were assembled using Bioedit software (www.mbio.ncsu.edu/ bioedit/bioedit) and Codon Code AlignerV.6.0.2 and compared with known BBTV isolates using bioinformatic tool (www.ncbi.nlm.nih.gov/BLAST). These sequences were aligned in a global multiple sequence alignment programme, Multalin (www.multalin.toulouse.inra,fr/multalin/). 
The phylogenetic analysis of twelve BBTV sequences was performed to understand the genetic grouping of BBTV-Assam isolates. Each of the twelve sequences of BBTVAssam isolates were compared separately with 11 full length sequences of respective genomic components (DNA 1-6) of the BBTV obtained from the nucleotide data base in the GenBank and used for different analyses. Six full length Banana bunchy top virus (BBTV) DNA 1-6 of Japan isolates were used as outgroup member.

The sequences were aligned in Clustal Walgorithm Sequence Alignment program using IUB matrix for DNA alignments in the Molecular Evolutionary Genetics Analysis Program (MEGA) version 6.06 (www.megasoftware.net) (Tamura et al., 2011).

Neighbor-Joining (NJ) analysis was carried out using Maximum Composite-likelihood model with uniform rates among the sites, the 1000 bootstraps replicates were used to evaluate the significance of generated tree.

\section{Results and Discussion}

The PCR analysis of the samples revealed that the BBTV primer pairs for the six components of BBTV (DNA1 to DNA6) genome successfully yielded 1111 to $1089 \mathrm{bp}$ products from all the 8 representative samples (Fig. 1 and 2). Uninfected sample designated as $\mathrm{H}$ did not yield any product.

All the six primer pairs detected the BBTV positive samples giving a band size of $1111 \mathrm{bp}$ for DNA 1, $1058 \mathrm{bp}$ for DNA 2, 1075 bp for DNA 3, 1046 bp for DNA 4, 1018 bp for DNA 5 and 1089 bp for DNA 6. About 130ng of total nucleic acids were used for amplification and thus, this result suggested that the PCR method enabled the detection of the BBTV infecting banana plants even at very low concentration of viral template.
Twelve representative BBTV isolates from Jahaji, Chenichampa and Malbhog viz., BBTV1JhDNA1, BBTV3JhDNA3, BBTV4JhDNA4, BBTV1CcDNA1, BBTV2CcDNA2, BBTV3CcDNA3, BBTV5CcDNA5, BBTV6CcDNA6, BBTV2MbDNA2, $\quad$ BBTV3MbDNA3, BBTV5MbDNA5 and BBTV6MbDNA6, respectively, were sequenced at Xcelris Genomics Ltd., Ahmadabad, Gujarat and Bioserve Biotechnology (I) Pvt. Ltd, Hyderabad and sequences of all the 12 products were assembled using Bioedit software (www.mbio.ncsu.edu/bioedit/bioedit) (Table 2). The results recorded a $1010 \mathrm{bp}, 975$ bp, 987 bp, 744 bp, 477 bp, 634 bp, 475 bp, 519bp, 669 bp, 358bp, 474 bp and 518 bp sequences for the twelve BBTV isolates of Assam.

The twelve sequences of BBTV were aligned using Multalin software (www.multalin.toulouse.inra,fr/multalin/). It was evident from the sequence similarity and phylogenetic analysis that BBTV Assam isolates showed 86-99 per cent homology with known isolates of the Pacific Indian Ocean (PIO) group of BBTV. Similar results were also reported by Selvaranjan et al., (2010) and Banerjee et al., (2014) for Indian isolates. Sequence similarity of BBTV1JhDNA1 and BBTV3JhDNA3 showed 98-99 per cent similarity with PIO group while, BBTV4JhDNA4 showed 93-99 per cent similarity with PIO group. Among the tested isolates, BBTV1CcDNA1 was found to have the least sequence similarity (86\%) with PIO group members followed by BBTV6CcDNA6 (89-92\%). The other BBTV isolates of Assam viz., BBTV2CcDNA2, BBTV3CcDNA3, BBTV5CcDNA5, BBTV2MbDNA2, BBTV3MbDNA3, BBTV5MbDNA5 and BBTV6MbDNA6 showed sequence similarity with PIO group members in the range of 9497, 96, 95-97, 91-94, 95-98, 93-95 and 96-98 per cent, respectively. 


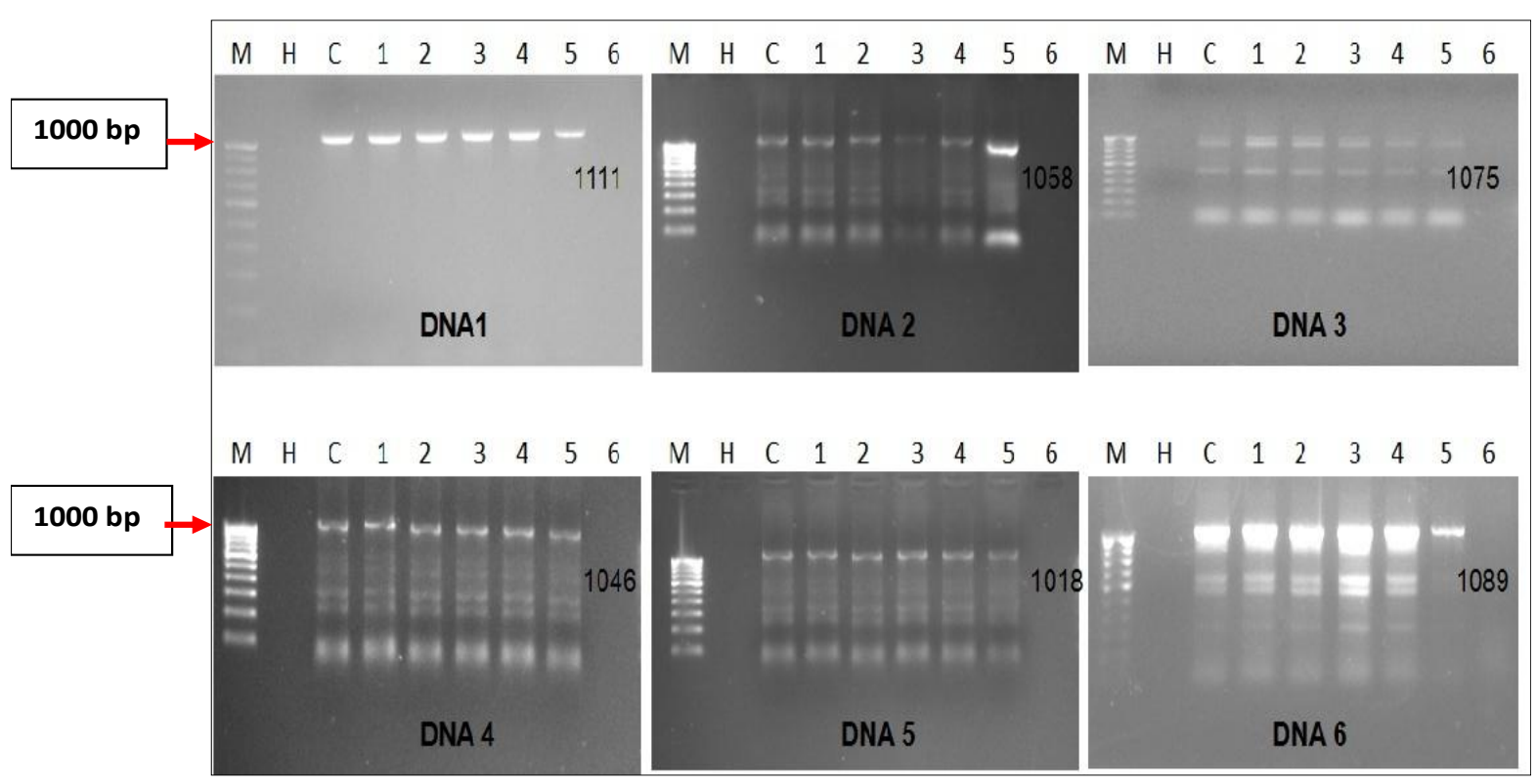

FIG.1. AGAROSE GEL ELECTROPHORESIS SHOWING AMPLIFIED PCR PRODUCTS OF DNA 1-6 OF BBTV ISOLATES FROM SIX BANANA CULTIVARS (REPRESENTATIVE SAMPLES). M: 100 bp LADDER, H: HEALTHY, C: POSITIVE CONTROL, LANE 1: JAHAJI, 2: MALBHOG, 3: CHENICHAMPA, 4: GRAND NAINE, 5: KACHKOL, 6: BHIMKOL

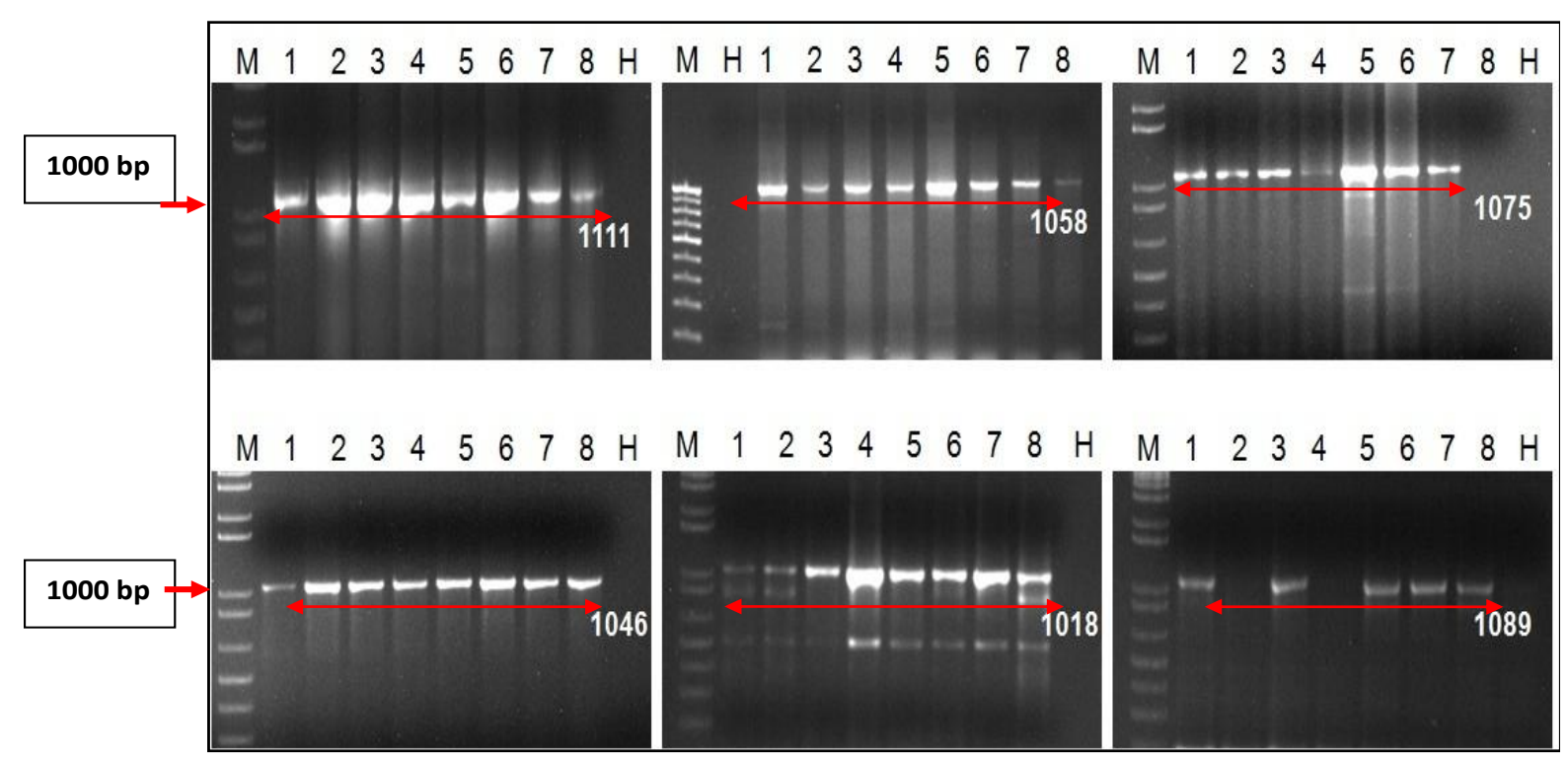

FIG.2. AGAROSE GEL ELECTROPHORESIS SHOWING AMPLIFIED PCR PRODUCTS OF DNA 1-6 OF BBTV ISOLATES FROM EIGHT DISTRICTS OF ASSAM (REPRESENTATIVE SAMPLES). M: 100 bp DNA LADDER, H: HEALTHY, LANE 1: JORHAT, 2: GOLAGHAT, 3: SONITPUR, 4: NAGAON, 5: MORIGAON, 6: KAMRUP METRO 7: KAMRUP RURAL \& 8: GOALPARA 


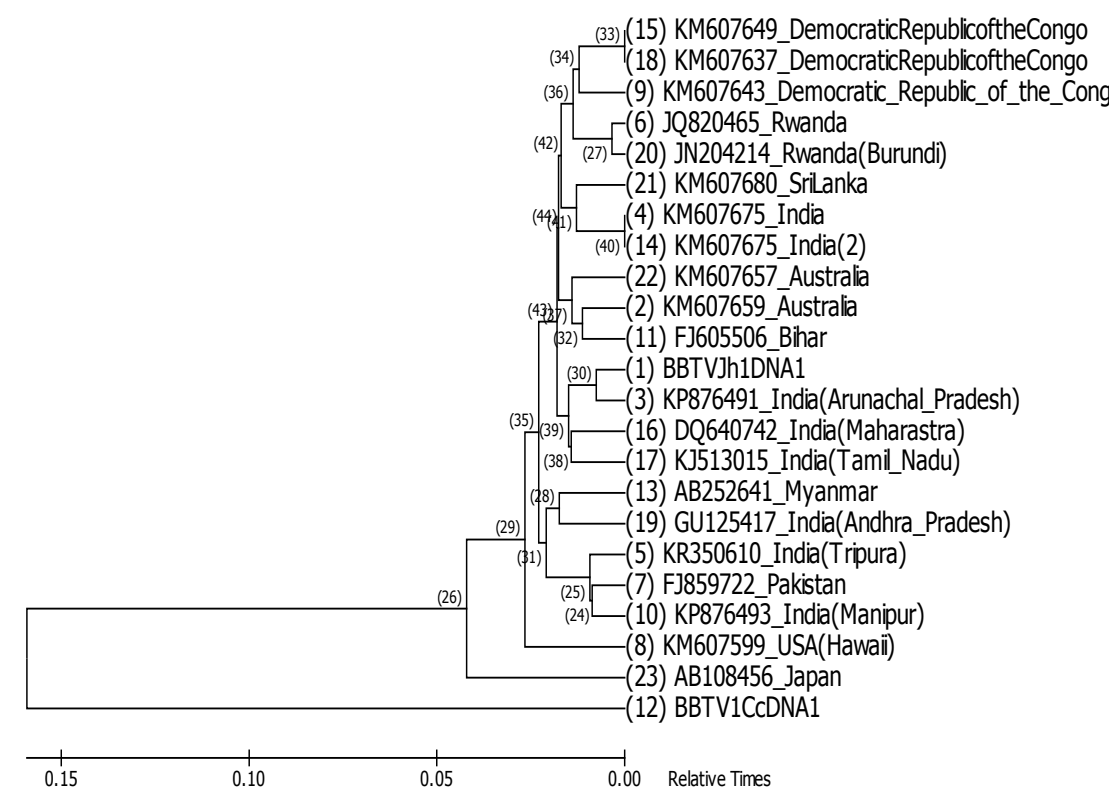

FIG.3. PHYLOGENETIC RELATIONSHIP OF BBTV1JhDNA1 AND BBTV1CCDNA1 ISOLATES OF ASSAM WITH OTHER KNOWN ISOLATES OF INDIA AND THE WORLD BASED ON BBTV DNA 1 USING NEIGHBOR-JOINING METHOD. SCALE BARS INDICATE THE EVOLUTIONARY DISTANCES WERE COMPUTED USING THE MAXIMUM COMPOSITE LIKELIHOOD METHOD AND ARE IN THE UNITS OF THE NUMBER OF BASE SUBSTITUTION PER SITE

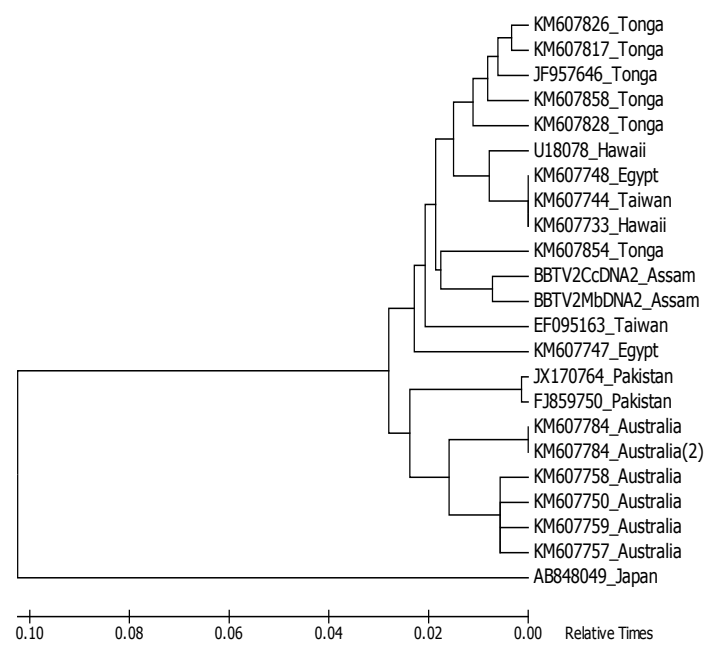

FIG. 4. PHYLOGENETIC RELATIONSHIP OF BBTV2CCDNA2 AND BBTV2MbDNA2 ISOLATES OF ASSAM WITH OTHER KNOWN ISOLATES OF INDIA AND THE WORLD BASED ON BBTV DNA 2 USING NEIGHBOR-JOINING METHOD. SCALE BARS INDICATE THE EVOLUTIONARY DISTANCES WERE COMPUTED USING THE MAXIMUM COMPOSITE LIKELIHOOD METHOD AND ARE IN THE UNITS OF THE NUMBER OF BASE SUBSTITUTION PER SITE 


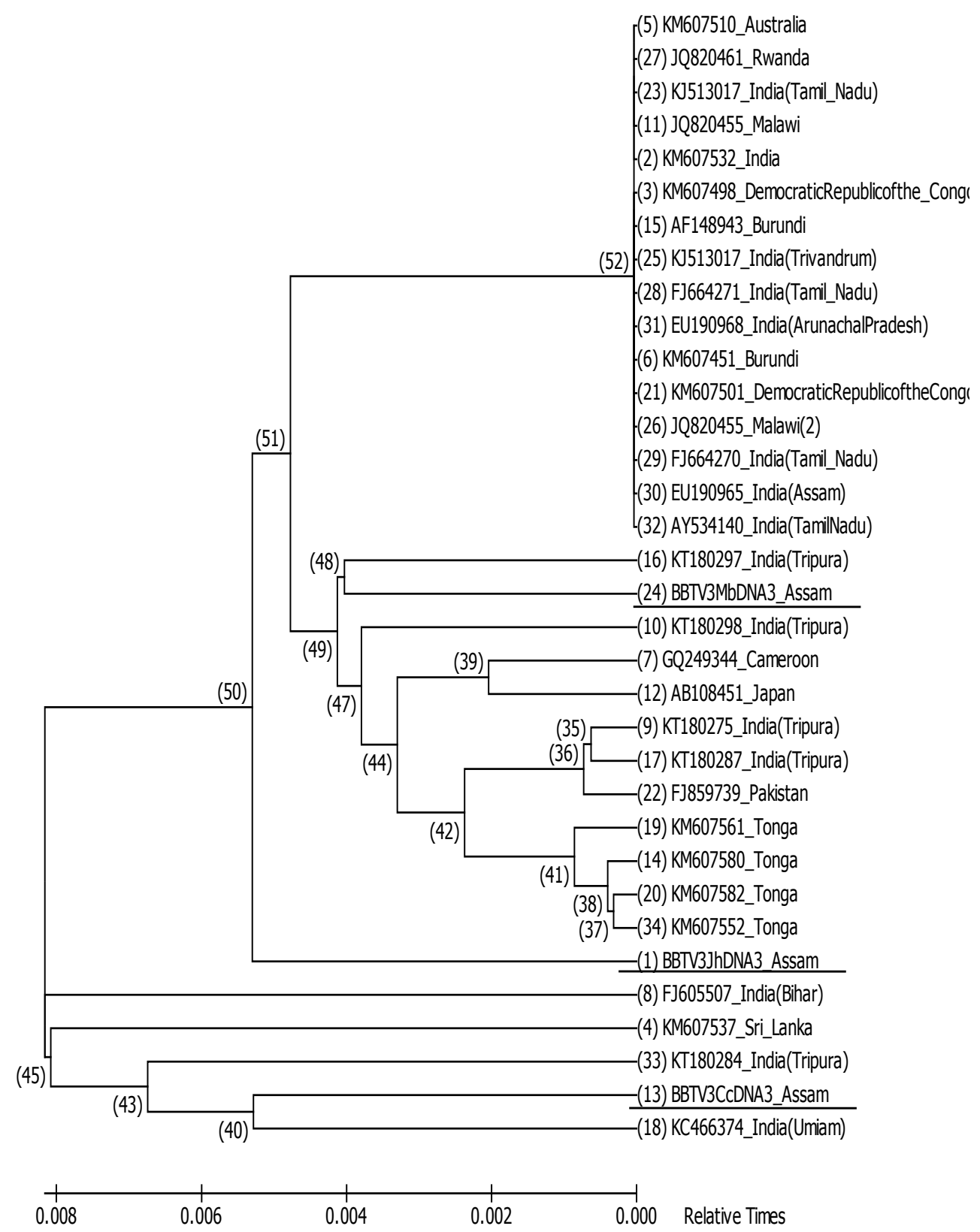

FIG. 5. PHYLOGENETIC RELATIONSHIP OF BBTV3JhDNA3, BBTV3CCDNA3 AND BBTV3MbDNA3 ISOLATES OF ASSAM WITH OTHER KNOWN ISOLATES OF INDIA AND THE WORLD BASED ON BBTV DNA 3 USING NEIGHBOR-JOINING METHOD. SCALE BARS INDICATE THE EVOLUTIONARY DISTANCES WERE COMPUTED USING THE MAXIMUM COMPOSITE LIKELIHOOD METHOD AND ARE IN THE UNITS OF THE NUMBER OF BASE SUBSTITUTION PER SITE 


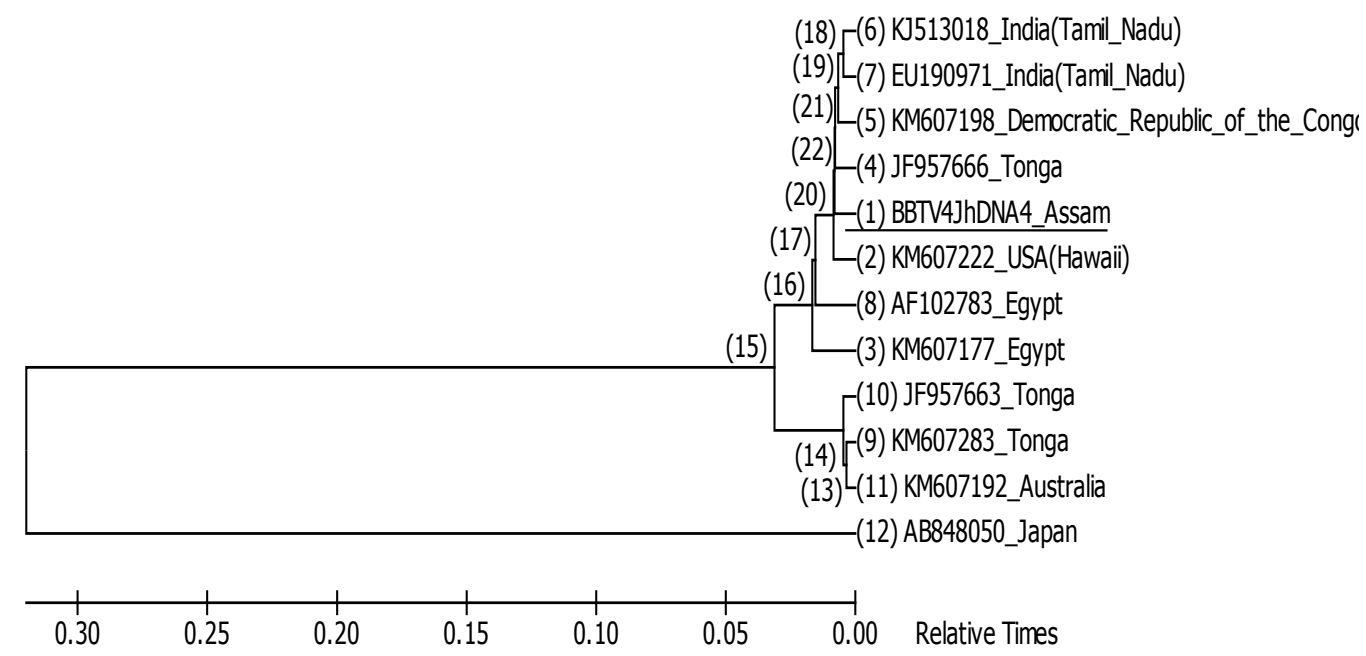

FIG. 6. PHYLOGENETIC RELATIONSHIP OF BBTV4JhDNA4 ISOLATE OF ASSAM WITH OTHER KNOWN ISOLATES OF INDIA AND THE WORLD BASED ON BBTV DNA 4 USING NEIGHBOR-JOINING METHOD.SCALE BARS INDICATE THE EVOLUTIONARY DISTANCES WERE COMPUTED USING THE MAXIMUM COMPOSITE LIKELIHOOD METHOD AND ARE IN THE UNITS OF THE NUMBER OF BASE SUBSTITUTION PER SITE

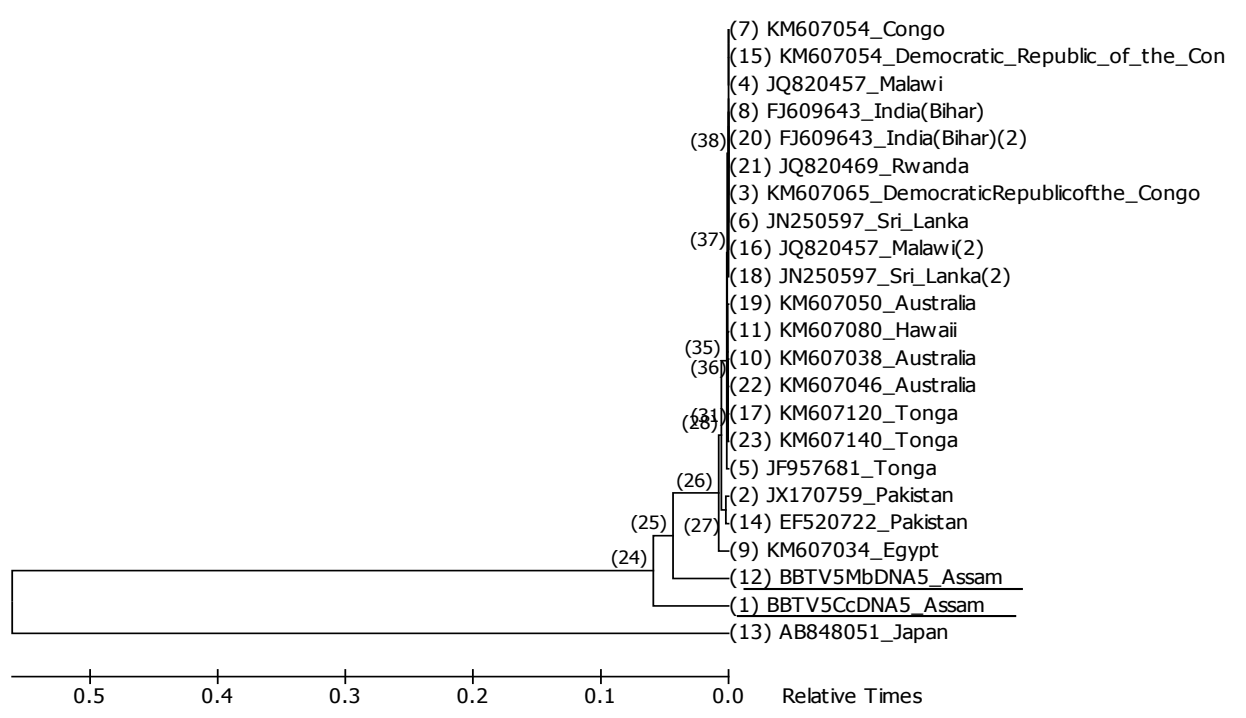

FIG. 7. PHYLOGENETIC RELATIONSHIP OF BBTV5CcDNA5 AND BBTV5MbDNA5 ISOLATES OF ASSAM WITH OTHER KNOWN ISOLATES OF INDIA AND THE WORLD BASED ON BBTV DNA 5 USING NEIGHBOR-JOINING METHOD. SCALE BARS INDICATE THE EVOLUTIONARY DISTANCES WERE COMPUTED USING THE MAXIMUM COMPOSITE LIKELIHOOD METHOD AND ARE IN THE UNITS OF THE NUMBER OF BASE SUBSTITUTION PER SITE 


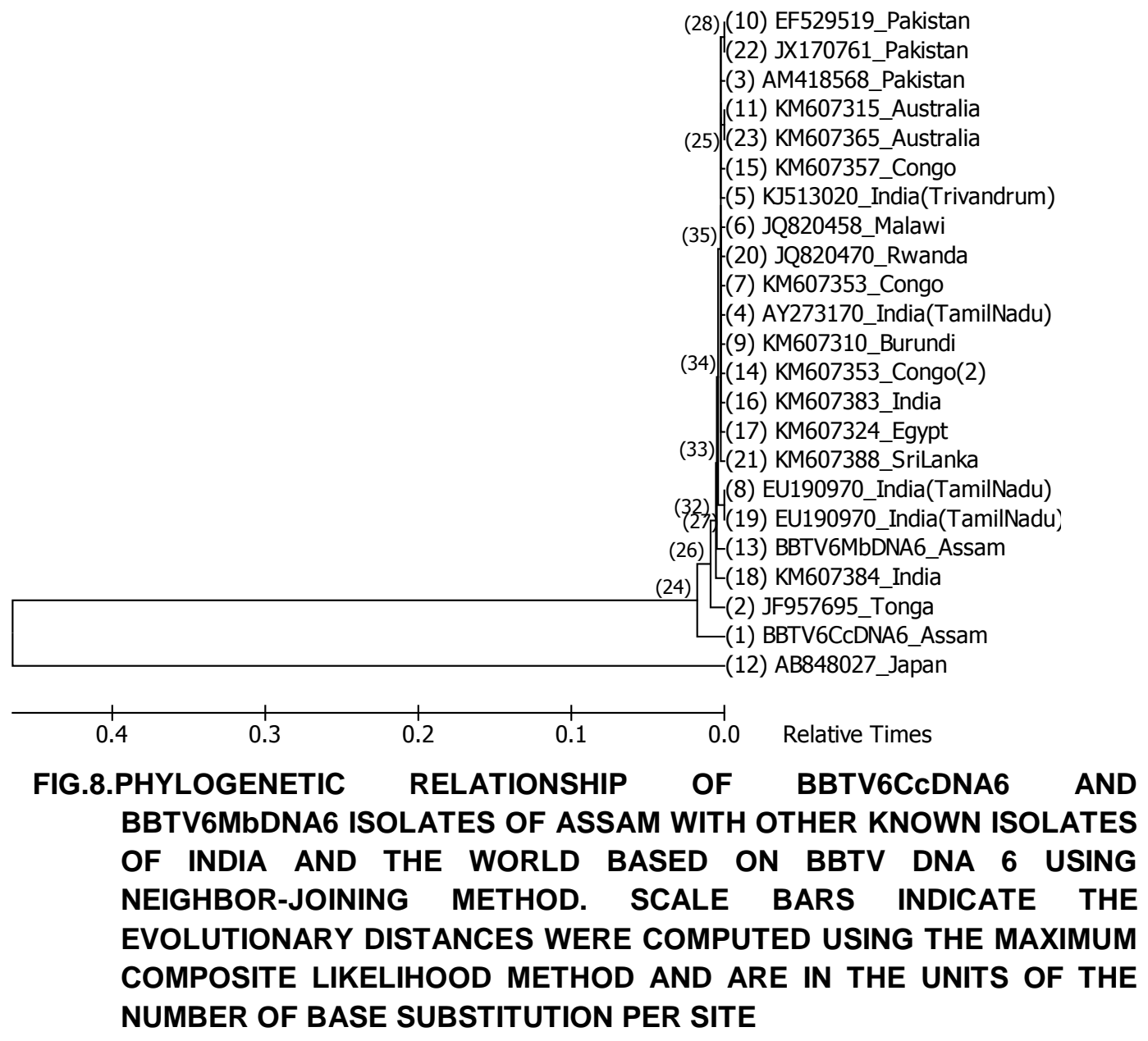

Table.1 List of primers used in PCR for detection of the Banana bunchy top virus (BBTV)

(Haq et al., 2010)

\begin{tabular}{l|l|c|}
\multicolumn{1}{|c|}{ Primer pair code } & \multicolumn{1}{|c|}{ Primer Sequence $\left(\mathbf{5}^{\prime} \mathbf{- 3}^{\prime}\right)$} & $\begin{array}{c}\text { Product } \\
\text { Size(bp) }\end{array}$ \\
\hline $\begin{array}{l}\text { BBTV } \\
\text { DNA-1/DNA R }\end{array}$ & $\begin{array}{l}\text { F - GGATGTTCACCATCAACAATCCC } \\
\text { R- TGCATACCACATATCGCGCCAT }\end{array}$ & 1111 \\
\hline $\begin{array}{l}\text { BBTV } \\
\text { DNA-2/DNA U3 }\end{array}$ & $\begin{array}{l}\text { F- GTAACCGGTCAACATTATTCTGGC } \\
\text { R- CTTGACCTTCGGTCATATCACG }\end{array}$ & 1058 \\
\hline $\begin{array}{l}\text { BBTV } \\
\text { DNA-3/DNA S }\end{array}$ & $\begin{array}{l}\text { F- ATCAAGAAGAGGCGGGTTGG } \\
\text { R- GGATTTCTTCGGATACCTAGCCAT }\end{array}$ & 1075 \\
\hline $\begin{array}{l}\text { BBTV } \\
\text { DNA-4/DNA M }\end{array}$ & $\begin{array}{l}\text { F- GTATATTAAGCAGCTCGTGAGG } \\
\text { R- TTCGGTACCTCAAAGAGCAAAACC }\end{array}$ & 1046 \\
\hline $\begin{array}{l}\text { BBTV } \\
\text { DNA-5/DNA C }\end{array}$ & $\begin{array}{l}\text { F- TGCCTGACGATGTCAAGAGAGAG } \\
\text { R- TAGCAGACCATTCCCAGAACTCC }\end{array}$ & 1018 \\
\hline $\begin{array}{l}\text { BBTV } \\
\text { DNA-6/DNA N }\end{array}$ & $\begin{array}{l}\text { F- CGCAAGG-TGGAAGAAAGTCGCCT } \\
\text { R- GCTCCAGAATCGACGCATGGTAC }\end{array}$ & 1089 \\
\hline
\end{tabular}


Table.2 Assembled sequences of twelve Banana bunchy top virus (BBTV) isolates of Assam

\begin{tabular}{|c|c|c|}
\hline Isolate & Sequence & $\begin{array}{c}\text { Number of base } \\
\text { pairs }\end{array}$ \\
\hline BBTV1JhDNA1 & 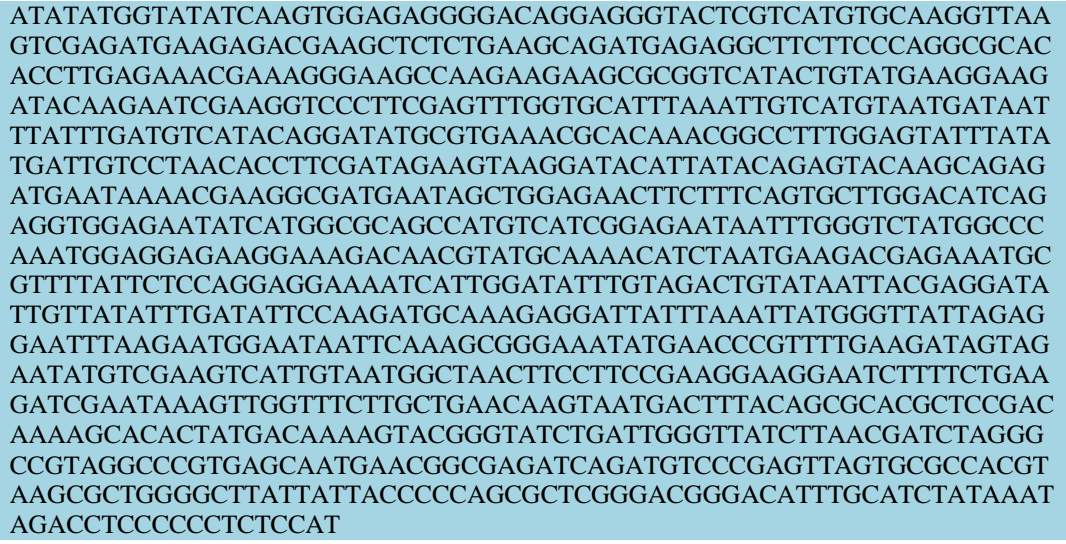 & 1010 bp \\
\hline BBTV3JhDNA3 & $\begin{array}{l}\text { CGAGCCACGACTACTCGTCGTTAGGGTCAATATTGGTTCCTGAAAACACCGTCAAGGT } \\
\text { ATTTCGGATTGAGCCTACTGATAAAACATTACCCAGATATTTTATCTGGAAAATGTTTA } \\
\text { TGCTTCTTGTGTGCAAGGTGAAGCCGGAAGAATACTTCATTGGGCTATGATCAAGAG } \\
\text { TTCTTGGGAAATCAACCAGCCGACAACGTGTCTGGAAGCCCCAGGTTATTATTAAAC } \\
\text { CTGAACATAGCCATCTGGTTAAACTGGTATGTAGTGGGGAACTTGAAGCAGGAGTCGC } \\
\text { AACAGGGACATCAGATGTTGAATGTCTTTTGAGGAAGACAACCGTGTTGAGGAAGAAT } \\
\text { GTAACAGAGGTGGATTATTTATATTTGGCATTCTATTGTAGTTCTGGAGTAAGTATAAA } \\
\text { CTACCAGAACAGAATTACATATCATGTTTGATATGTTATGTAAACATAAACTATTGTA } \\
\text { TGGAATGAAATCCAAATAACATACAACACGCTATGAAATACAAGACGCTATGACAAA } \\
\text { AGTACGGGTATCTGATTAGGTATCCTAACGATCTAGGGCCGAAGGCCCGTGAGCAATA } \\
\text { TGCGTCGAAATAATGTTAACAAACAAATATACATGATACGGATAGTTGAATACATAA } \\
\text { ACAACGAGGTATATAATACAACAAACTGTTGTAAAGAAATAAAAAATAAGAAGAGAG } \\
\text { AGTATATTTGTGTCGGATAAGCATGACACCCACCACTTTAGTGGTGGGTCAGATGTCCC } \\
\text { GAGTTAGTGCGCCACGTAAGCGCTGGGGCTTATTATTACCCCCAGCGCTCAGGACGGG } \\
\text { ACATGGGCTAATGGATTGTGGATATAGGGCCCAAAGGGCCCGTTTAGGTGGGTTTTGG } \\
\text { GCTTATGGGCTTTATCCAGAAGACCAAAAACAGGCGGGAACCGTCCCAAATTCAAACT } \\
\text { TCGATTGCTTGCCCTGCAAGCCATCTAGAAGTCTATAAATACCA }\end{array}$ & 975 \\
\hline BBTV4JhDNA4 & 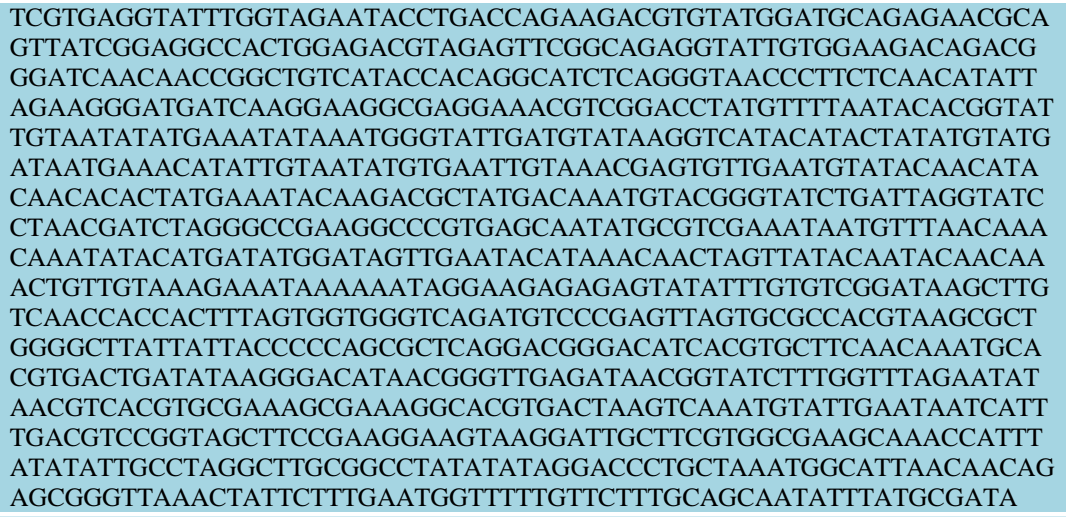 & 987 bp \\
\hline BBTV1CcDNA1 & $\begin{array}{l}\text { ACCCACGGGGGGGGGAGAGGAAAAGAAAAAATATATGGTATATCAAGTGGAGAGGGG } \\
\text { ACAGGAGGGTACTCGTCATGGGCAAGGTTATGTCCAGATGAAGAGACGAAGTTCTCTG } \\
\text { AAGCAGATGAGAGGCTTCTTCCCAGGCGCACACCTTGACAAACGAAAGGGGAGCCAA } \\
\text { AAAAAAACCCGGTCATACTGGATGAAGGAAAATACAAGAATCGAAGGTCCCTTCGAG } \\
\text { TTTGGTGAATTTATATTTTGCTGAAAAGGAAATTTATTTTATTCCATACCGGGTATGGCT } \\
\text { TGAACCCTCCAAAGGGACTTTGGCGTTTTAATTGGATTGGCCTAACCCCTTCAAAAGAA } \\
\text { AAAGGGGTTCATTTTTCCAGTTCCAAATTAAGCCTTTTAAAATGCCGGGAATACCC } \\
\text { AGTGGGAAAATACTCCCTTGCTGGAAAAAAAAGGGGGAAAACAAGGCCCAACTTT } \\
\text { TTCATCCAAAAAAATTCGCGTCTATTCCCCAAGGAAAAAAAACAAAGTCACCGTAGG } \\
\text { CAAAACATGTAAGGAAGACAAGACTGTCTTTCCTCAAGAAGGAAATAACCCAAATTG } \\
\text { GCACCGGGAACTGCCACGCACTGACATTTTCACAATTCAGGACAAAGCAGAATAGATA } \\
\text { CTCAGGGATATAACGCATAAAAGGATCACTAAGCGGCAATAGACTCTCTACATATTGA } \\
\text { AGTTTCACACCCTGTAGTCACTTGCGCCGTAGGGAGTACTGTAGAAA }\end{array}$ & 744 bp \\
\hline BBTV2CcDNA2 & $\begin{array}{l}\text { ACATTTAATCTCAAAAAAGATGCCTGGTCAAGGATAATTGCTCTCTCTCTTCTGTCAAG } \\
\text { GTGGTTGTGCTGAGGCGGAAGATCGCCAGCGGCGATCGTCGGAACGACACTGCATCTA } \\
\text { GAGAGGCGGCGAGGAAACTACGAAGCGTATATCTGGTATTTATAGACTTATAGCGTAG }\end{array}$ & 477 bp \\
\hline
\end{tabular}




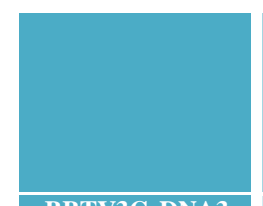

BBTV3CcDNA3

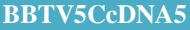

BBTV6CcDNA6

BBTV2MbDNA2

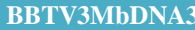

BBTV5MbDNA5

BBTV6MbDNA6
CTAGAAGTATACACTGTGCAGATATTGTATTTTGTAAATTACGAACAAATTCGTATATG ATATTAATAAAACAACTGGGATTGTTAATGTTTACATTAACTAGTATCTTTTATGTACA AAGTTAAATAGAGTATACGGAACGTATACTAATAAAAAAATTAAATGACAGGCGAAG CATGATTAACAGGTGTTTAGGTATAATTAACATAATTATGTCAAGTAATTATAATACGG AAAATGAATAGGTATGAGGTGAAAGAGGAGATATTAGAATATTTAAAAACCCAATTTA TATTATTTGG

TAAAGCGGGATTCGAGCCTACTGATAAAACATTACCCAGATATTTTATCTGGAAAATG TTTATGCTTCTTGTGTGCAAGGTGAAGCCCGGAAGAATACTTCACTGGGCTATGATCAA GAGTTCTTGGGAAATCAACCAGCCGACAACATGTTTGGAAGCACCAGGTTTATTTATA AAACCTGAACATAGCCATCTTGTTAAACTGGTATGTAGTGGGGAACTTGAAGCAGGAG TCGCAACAGGGACATCAGATGTTGAATGTCTTCTGAGGAAGACAACCGTGTTGAGGAA GAATGTAACGGAGGTGGATTATTTGTATTTGGCATTTTATTGTAGTTCTGGAGTAAGTA TAAACTACCAGAACAGAATTACATATCATGTATGATATGTTTATGTAAACATAAACTAT TGAATGGAATGAAATCCAAATAACATACAACACGCTATGAAATACAAGACGCTATGAC AAATGTACGGGTATCTGATTAGGTATCCTAATGTTCTAGGGCCGAAGGCCCGTGAGCA ATATACGTCGAAATAATGTTTAATAAACAAAATATACATGATACGGATAGTTGAATAC ATAAAACAACGCTGTATATAAAACAACAAAAATGTTGTAAAGAAATAAAAA

AATGAAATATTGGGAGACGGAGAACTTCTGTTCTGTCAGAAGTTGAAGAGCTATGTCA GAAGGATGCTTGCCTACGGAGATCAGGAGGATGCCCTTGCTGGAGTGAAGGATATGAA GACTTCTATTATTCGCTATAGCGAATACTTGAAGAAACCATGTGTGGTAATTTGTTGTG TTAGCAATAAATCAATTGTGTATAGGTTAAACAGCATGGTGTTCTTTTATCATGAATAC CTTGAAGAACTAGGTGGTGATTACTCAGTATATCAAGATCTCTATTGTGATGAGGTTCT CTCTTCTTCATCGACAGAGGAAGAAGATGTAGGAGTAATATTTAGGAATGTTATCATG GCATCGACACAAGAGAAGATCTCTTGGAGTGATCGTCAAAAGATTGTAGTGGCGTAGA ATTAAGAGACGGTTGTCGGTTGTGTTTTGATTAATAATGAAAAAAAAATTGAGTTTGTT GATTAAG

TGTTCCTTGGATTATTGAGCTGTGTTTACGGAAGCTTCAGCGGAAATAATAGGAACGTT CGTGGATTTCTCTACGTATCGATCAGAGACGATGACGGAGAAATGCGTCCAGTACTCA TAGTACCATTCGGAGGATATGGATATCATAATGATTTCTATTATTTCGAAGGAAAGGG GAAAGTTGAATGTGATATATCATCAGATTATGTTGCGCCAGGAATAGATTGGAGCAGA GACATGGAAGTTAGTATTAGTAACAGCAACAACTGTAATGAATTATGTGATCTGAAGT GTTATGTTGTTTGTTCTTTAAGAATCAAGGAATAAAAGTTGTGCTGTAATGTTTATTAA TAAAACTCACCTTTGGGAAATTGATAGTTGTATCATACGTCCAACACACCCTGATCCAG GACACGCTATGTACAATGTACGGGGATCTGTTTTTTTTTTTTACTTGCGCTTAACGGCCC CCCGCCCGATGAACAAAAATCGAGTAGTTATATCTGCTTTCTTCATGCTA

CAAAAAGAGGGCCTGGTGCAAGGATAATTGGCTCTCTCTCTTCTGTCACCGTGGTTGTG CTGAGGCGGAAGATCGCCAGAGGCGAGTGTCGGAACGACACTGCATCTAGAGAGGCG GCGAGGAAACTACGAAGCGTATATCGGGTATTTATAGACTTATAGCGTAGCTAGAAGT ATACACTGTACAGATATTGTATTTTGTAAATTACGAACAAATTCATATATGATATTAAT AAAACAACTGGGATTGTTAATGTTTACATTAACTAGTATCTTTTATGTACAAATTAAAA TACAGTATACGGAACGTATACTAATGAAAAAATTAAATGACAGGAGAAGCATGTTTAA CAGGTGTTTAGGTATAATTAACATAATTATGTCAAGTAATTATAATACGGAAAATGAA TAAGTATGAGGTGAAAGAGGAGATATTAGAATATTTAAAAACCCAATTATATTATTTT GGAACGAAATACAACACGCTATGAAATACAAGACGCTATGACAAATGTACGGGTATCT GATTAGGTATCTTAACGCTTAAGGCCCGCAGGACCGTCAAGTGAAAGGAACGGTCCAT ATTAATTCCTTAGCGACGATGAGGGAATCTTAAGGAGGACCACTTAATGACTGCTGTC ATTGATCAAATAGTTACGTATTTCCAACG

GGCAAAGAGGCGCCAGGCACCAACCAGCCACAACTACTCGTCGTTAGGGTCAATATTG GTTCCTGAAAACACCGTCAAGGTATTTCGGATTGAGCCTACTGATAAAACATTACCCA GATATTTTATCTGGAAAATGTTTATGCTTCTGGTGTGCAAGGTGAAACCCGGAAAAATA CTTCATTGGGCTATGATCAAGAGTTCTTGGGAAATCAACCAGCCGACAACCTGTCTGG AAGCCCCAGGTTTATTTATTAAACCTGAACATAGCCATCTGGTTAAACTGGTATGTAGT GGGGAACTTGAAGCAGGAGTCGCAACAGGGACATCAAATGTTGAATGTCTTCTGAGGA ATATTCCG

CCGTGTATATTGGGGAGACGGAGAACTTCTGTTCTGTCAGAAGTTGAAGAGCTATGTC AGAAGGATGCTTGCCTACGGAGATCAGGAGGATGCCCTTGCTGGAGTGAAGGATATGA AGACTTCTATTATTCGCTATAGCGAATACTTGAAGAAACCATGTGTGGTAATTTGTTGT GTTAGCAATAAATCAATTGTGTATAGGTTAAACAGCATGGTGTTCTTTTATCATGAATA CCTTGAAGAACTAGGTGGTGATTACTCAGTATATCAAGATCTCTATTGTGATGAGGTTC TCTCTTCTTCATCGACAGAGGAAGAAGATGTAGGAGTAATATTTAGGAATGTCTTCCTC GCATCGAGACAAAAGAACTTCTCTTGGAGTGATTGTACGAAGATTATTATATCAGACT ATTAAGAAAGATTTCCCTGTGGTTTTTTTTTTTCAGCCTAACGTAACCGGGAAGGGATT AAGAA

CAATCCTAAATCATTGAGCTGTGTTTACGGAAGCTTCAGCGGAAATAATAGGAACGTT CGTGGATTTCTCTACGTATCGATCAGAGACGATGACGGAGAAATGCGTCCAGTACTCA TAGTACCATTCGGAGGATATGGATATCATAATGATTTCTATTATTTCGAAGGAAAGGG GAAAGTTGAATGTGATATATCATCAGATTATGTTGCGCCAGGAATAGATTGGAGCAGA GACATGGAAGTTAGTATTAGTAACAGCAACAACTGTAATGAATTATGTGATCTGAAGT GTTATGTTGTTTGTTCTTTAAGAATCAAGGAATAAAAGTTGTGCTGTAATGTTTATTAA TAAAACGTATATTTGGGAAATTGATAGTTGTATAAAACATACAACACGCTATGAAATA CAAGACGCTATGACAAATGTACGGGTATCTGAATGAGTTTTTGTATCGCTTAAGGGCC GCACGCCCGTCGAAAAATAATCATCGAGTTATTAACGTTTGATACTCATCCGA

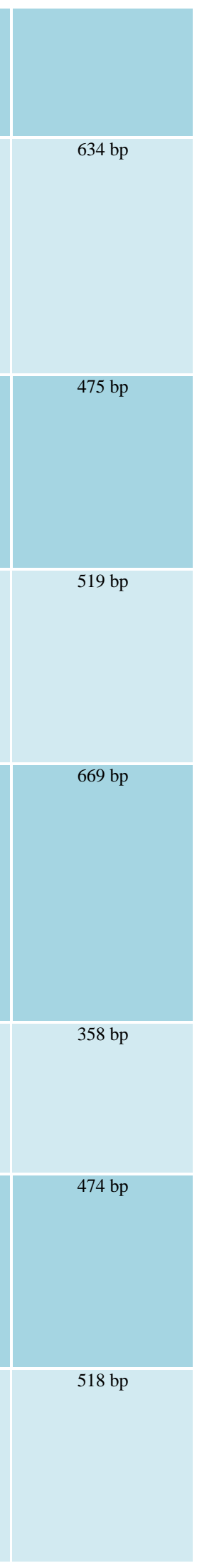


However, the twelve sequence products compared with known Indian isolates (under PIO group) revealed that the isolates, BBTV1JhDNA1, BBTV3JhDNA3 showed 98-99 per cent and BBTV4JhDNA4 showed 97 per cent homology with isolates from India. The Assam isolates viz., BBTV1CcDNA1, BBTV3CcDNA3, BBTV5CcDNA5, BBTV6CcDNA6, BBTV3MbDNA3, BBTV5MbDNA5 and BBTV6MbDNA6 showed 86, 96, 96, 91-98, 96-98, 94 and 97 per cent homology with Indian isolates, respectively., This suggested that genetic variability exist among the BBTV isolates of Assam.

Further, six phylogenetic trees were constructed using the DNA 1-6 of BBTV isolates of Assam with ten isolates as members from PIO group and one isolate from SEA group (Japan as outgroup member). It was evident from the Figure 3 that BBTV DNA1 isolates of Assam viz., BBTV1JhDNA1 and BBTV1CcDNA1 were located in two different clusters. The phylogenetic analysis indicated that BBTV1CcDNA1 formed into a distinct separate cluster whereas remaining Indian isolates including BBTV1JhDNA1 of Assam formed the core of PIO group. The Assam isolates of BBTV DNA2 viz., BBTV2CcDNA2 and BBTV2MbDNA2 were grouped together (Fig. 4) and showed close phylogenetic proximity with PIO group members but more closer to isolate KM607854 from Tonga (PIO group). However, BBTV2CcDNA2 and BBTV2MbDNA2 also showed phylogenetic proximity towards the members South-East Asian (SEA) group (Taiwan isolates). The phylogenetic analysis of BBTV DNA3 isolates of Assam viz., BBTV3JhDNA3, BBTV3CcDNA3 and BBTV3MbDNA3 revealed that they were grouped into separate clusters and belonged to PIO group of BBTV (Fig. 5). It was evident from the Figure 5 that
BBTV3JhDNA3 grouped into a separate cluster but showed closer phylogenetic proximity towards isolates of Tonga (KM607552) and Bihar, India (FJ605507) while BBTV3CcDNA3 and Umiam (India) isolate KC466374 grouped together and formed into a separate cluster. On the other hand, BBTV3MbDNA3 and isolate KT180297 from Tripura (India) grouped together and formed into a separate cluster. The only BBTV DNA4 isolate of Assam i.e., BBTV4JhDNA4 showed close phylogenetic proximity towards the members of PIO group (Fig. 6). From the Figure 7 it was found that BBTV DNA5 isolates of Assam viz., BBTV5CcDNA5 and BBTV5MbDNA5 were distinct members of PIO group and formed separate clusters individually. The phylogenetic analysis of BBTV DNA6 isolates of Assam viz., BBTV6CcDNA6 and BBTV6MbDNA6 revealed that these two isolates were also distinct members of PIO group of BBTV and grouped in separate clusters individually (Fig. 8). The BBTV6CcDNA6 showed close phylogenetic proximity with the Tonga isolate (JF957695) whereas, the BBTV6MbDNA6 showed close phylogenetic proximity with isolate EU190970 from Tamil Nadu, India.

Several reports showed that variation in the sequences of BBTV genome was common among the isolates from the same region ( $\mathrm{Su}$ et al., 2003). However, BBTV2CcDNA2 showed 95 per cent similarity with Taiwan (EF0915163.1) isolate and BBTV2MbDNA2 showed 94 per cent similarity with Taiwan (KM607744.1) isolate which were members of SEA group. This genetic distinctiveness of the BBTV-Assam isolates could have been resulted due to differential evolution of BBTV in this geographically isolated NE region of India as reported by Banerjee et al., (2014). Generally, the distribution of PIO group BBTV isolates occurs across the natural geographical range of Musa 
balbisiana, whereas the SEA group isolates occur across $M$. balbisiana and M. acuminata range. Also, the global distribution of BBTV has been artificially expanded by the trade and transport of infected planting materials and aphids to region outside its vector's normal range. The banana germplasm of NE India comprises mostly the hybrids of $M$. balbisiana from Indian subcontinent and $M$. acuminata from South-East Asia (Molina and Kudagamage, 2002). Although the region shares the boundary with China, Myanmar and Bangladesh, it is being isolated by the hills and mountains restricting vector movement as well as transport of planting materials. In India, BBTV has been prevalent since 1943 and so it is possible that genetic variability such as that observed among the other reported Indian isolates exists among the isolates of the Assam also. These results conformed to those described by Selvaranjan et al., (2010) and Vishnoi et al., (2009). They related this variability among the Indian isolates might be due to the presence of BBTV in India for an extended period of time.

\section{References}

Akram, M. and Kumar, R. 2006.Banana bunchy top disease: field diagnosis and management. Indian Farming, 56: 1214.

Allen, R.N. 1987. Further studies on epidemiological factors influencing control of banana bunchy top disease and evaluation of control measures by computer simulation. Aus. J. Agric. Res., 38: 373-382.

Banerjee, A., S. Roy, G. T. Behere, S. S. Roy, S. K. Dutta and Ngachan, S. V. 2014. Identification and characterization of a distinct banana bunchy top virus isolate of Pacific-Indian Oceans group from North-East India. Virus Research, 183: 41-49.
Beetham, P. R., Harding, R.M. and Dale, J.L. 1999. Banana bunchy top virus DNA 2 6 are monocistronic. Arch. Virol., 144: 89-105.

Dale, J. L. and Harding, R. M. 1998. Banana bunchy top disease: Current and future strategies for control. In: Plant Virus Disease Control. Hadidi, A., Khetarpal, R. K. and Koganezawa, H. (Eds.) American Phytopathological Society, pp 659-669.

Dale, J.L. 1987. An economically important tropical plant virus disease. Adv. Virus Res., 33: 301-325.

Haq, R.; Islam, Md. N.; Naqvi, A. R.; Jan, A. T. and Rizwanul, Md. Q. (2010). Genetic diversity and possible evidence of recombination among Banana Bunchy Top Virus (BBTV) Isolates. International Research Journal of Microbiology, 1(1): 001-012.

Karan, M.; Harding, R.M. and Dale, J.L. (1997). Association of Banana bunchy top virus DNA components 2 to 6 with banana bunchy top disease. Molecular Plant Pathology. Online [http://www.bspp.org.uk/mppol].

Khalid, S. and Soomro M. H. (1993). Banana bunchy top disease in Pakistan. Plant Path., 42: 923-926.

Khalid, S., M.H. Soomro and Stover, R. H. 1993. First report on Banana bunchy top virus in Pakistan. Plant Dis., 77: 101.

Lokeswari, T.S., J. Anandhi, C. Vijila and Viswanath, G. S. (2007). Screening banana plants for Banana bunchy top virus with primers specific to Indian isolates. Journal of Plant Diseases and Protection, 114(3): 101-107.

Magee, C.J.P. 1927. Investigation on the bunchy top disease of banana. Council for Scientific and Industrial Research, Melbourne, Australia, p. 86.

Molina, A. B. and Kudagamage, C. 2002. The international network for the improvement of banana and plantain 
(INIBAP): PGR activities in South Asia. In: South Asia Net-work on Plant Genetic Resources (SANPGR) meeting held on December 9-11 at Plant Genetic Resources Center (PGRC), Peradeniya, Sri Lanka, pp 1-7.

NRCB. 2012. National Research Centre for Banana, Trichy, ICAR, India. Banana Scenario, 2012 [http://www.nrcb. res.in/].

Selvarajan, R., M. M. Sheeba, V. Balasubramanian, R. Rajmohan, N. L. Devi, and Sasireka, T.2010. Molecular characterization of geographically different Banana bunchy top virus isolates in India. Indian J. Virol., 21(2): $110-116$.

Su, H. J., L.Y. Tsao, M. L. Wu and Hung, T. H. 2003. Biological and molecular categorisation of strains of Banana bunchy top virus. Journal of Phytopathology, 151: 290-296.

Tamura, K., D. Peterson, N. Peterson, G. Stecher, M. Nei, and Kumar, S. 2011.
MEGA5: molecular evolutionary genetics analysis using maximum likelihood, evolutionary distance, and maximum parsimony methods. Molecular Biology and Evolution, 28: 2731-2739.

Thomas, J. E. and Dietzen, R. G. 1991. Purification, characterization and serological detection of virus like particles associated with Banana bunchy top disease in Australia. J. Gen. Virol., 72:217-224.

Thomas, J. E., M. L. Iskra-Caruana and Jones, D. R. 1994. Banana bunchy top disease. Musa Disease Fact Sheet No.2. Montpellier, France: INIBAP.

Vishnoi, R., S.K. Raj and Prasad, V. 2009. Molecular characterization of an Indian isolate of banana bunchy top virus based on six genomic DNA components. Virus Genes, 38 (2): $334-$ 344.

\section{How to cite this article:}

Nilakshi Kakati and Nath, P.D. 2018. Genetic Diversity of Banana Bunchy Top Virus (BBTV) Prevalent in Assam Causing Banana Bunchy Top Disease. Int.J.Curr.Microbiol.App.Sci. 7(11): 1547-1560. doi: https://doi.org/10.20546/ijcmas.2018.711.178 